\begin{tabular}{|c|c|c|}
\hline \multirow{3}{*}{$\begin{array}{r}\text { Case Reports in } \\
\text { Gastroenterology }\end{array}$} & \multicolumn{2}{|c|}{ Case Rep Gastroenterol } \\
\hline & DOI: 10.1159/000444444 & $\begin{array}{l}\text { ( ) } 2016 \text { The Author(s) } \\
\text { Published by S. Karger AG, Base } \\
\text { www.karger.com/crg }\end{array}$ \\
\hline & $\begin{array}{l}\text { This article is licensed } \\
\text { International License }(C C \\
\text { Usage and distribution fo }\end{array}$ & $\begin{array}{l}\text { nons Attribution-NonCommerc } \\
\text { ger.com/Services/OpenAccessli } \\
\text { uires written permission. }\end{array}$ \\
\hline
\end{tabular}

Published: $\operatorname{man} \mathbf{2 0 1 6}$

\title{
Clinical Evaluation of Hepatic Portal Venous Gas after Abdominal Surgery
}

\author{
Satomi Okadaa, Takashi Azuma $^{a}$ Yujo Kawashita ${ }^{a}$ \\ Shigetoshi Matsuo a Susumu Eguchib \\ ${ }^{a}$ Department of Surgery, Nagasaki Prefecture Shimabara Hospital, Shimabara City, Japan; \\ ${ }^{b}$ Department of Surgery, Nagasaki University Graduate School of Biomedical Sciences, \\ Nagasaki City, Japan
}

\section{Keywords}

Hepatic portal venous gas $\cdot$ Abdominal surgery $\cdot$ Postoperative complications

\begin{abstract}
Hepatic portal venous gas (HPVG) is induced by various abdominal diseases. Since HPVG is accompanied by bowel ischemia, intestinal infection and hypovolemia, various modes of critical management are needed to treat the underlying conditions. HPVG associated with abdominal complications after surgery has rarely been reported. We present 4 patients with HPVG after abdominal surgery: 2 of the 4 patients died of multiple organ failure, and the other 2 recovered with solely conservative therapy. Although postoperative HPVG is a severe and life-threatening condition, early detection and systemic treatment lead to a better patient outcome.

(C) 2016 The Author(s)

Published by S. Karger AG, Basel
\end{abstract}

\section{Background}

Hepatic portal venous gas (HPVG) was first described by Wolfe and Evans [1] in 1955 in infants with fatal necrotizing enterocolitis and was found to have a $75 \%$ mortality rate [2]. The development of imaging techniques enables earlier detection of even minute quantities of air in the portal system, resulting in a significant reduction in mortality [3]. HPVG is induced by various abdominal conditions such as bowel ischemia, inflammatory bowel diseas- 
es, bowel obstruction, diverticulitis, appendicitis, intra-abdominal abscess and gastric dilatation [3-6]. Because HPVG is accompanied by bowel ischemia, intestinal infection and hypovolemia, various modes of critical management are needed to ensure recovery in parallel with treatment of the underlying conditions. Recently, many researchers have comprehensively described the pathophysiology of HPVG. However, there is scant literature on HPVG induced by postoperative complications after abdominal surgery. We report 4 patients with HPVG occurring after abdominal surgery. We describe the clinical course of their postoperative complications resulting in HPVG and unique therapeutic options for this severe condition.

\section{Case Reports}

Case 1

A 70-year-old woman underwent pylorus-preserving pancreatoduodenectomy for bile duct carcinoma. Enteral nutrition through the intraoperatively placed jejunostomy tube was started on postoperative day (POD) 1.

On POD 4, she complained about abdominal discomfort. It first improved after defecation, but abdominal distension was observed subsequently and gradually aggravated. On the morning of POD 5, she suddenly developed loss of consciousness accompanied by hyperventilation and general cyanosis, which we considered to be a hypovolemic shock of unknown origin. Fluid resuscitation with the administration of catecholamine did not improve her general condition.

During the afternoon of POD 5, she developed oliguria. On physical examination, we observed abdominal distension, tenderness and mild muscle defense. Computed tomography (CT) showed diffuse intraluminal gas in the gastrointestinal tract from the lower esophagus to the ileocecal portion and portal venous gas infiltrating the bilateral lobes of the liver (fig. $1 \mathrm{a}, \mathrm{b})$. An emergent laparotomy was performed, and piebald ischemia of the intestinal wall was observed from the stomach to the ileocecal portion with a marked stench. A tentative diagnosis of nonocclusive mesenteric ischemia was made, and extensive resection of the small intestine was performed. After surgery, we continued fluid resuscitation with administration of catecholamine, but her general condition did not improve. She died of multiple organ failure on the evening of POD 5.

Case 2

An 82-year-old woman with a history of hypertension and type II diabetes mellitus underwent total gastrectomy with Roux-en-Y reconstruction for advanced gastric carcinoma. Oral intake was started on POD 2, but she developed aspiration pneumonia that was treated with an antibiotic. Enteral nutrition through the jejunostomy tube placed during surgery was started from POD 3.

On POD 6, she restarted oral intake because aspiration pneumonia was healed. But on POD 8, she developed severe diarrhea. Although she was treated conservatively with sufficient intravenous infusion, her general condition was abruptly exacerbated by the appearance of multiple organ dysfunction. On POD 15, CT revealed diffuse intraluminal gas in the small intestine and portal venous gas infiltrating the bilateral lobes of the liver (fig. 1c, d). Finally, she died of multiple organ failure on POD 18. 
Case 3

An 81-year-old man with no previous history was admitted to our institution for treatment of advanced gastric cancer with pyloric obstruction. A nasogastric tube was inserted to relieve nausea and vomiting, yielding approximately $1,000 \mathrm{ml}$ of tan-colored gastric juice per day. He underwent further evaluation of TNM staging and preoperative risk factors, and the dehydration induced by the loss of gastric juice was resolved. On the 11th day after admission, he developed septic shock following urinary tract infection, which was treated by fluid resuscitation and administration of a broad-spectrum antibiotic. He had recovered by the 14th day with this conservative therapy. Radiologic examinations revealed no distant metastasis or peritoneal dissemination, and on the 18th day, he underwent laparotomy. Although the main lesion showed infiltrative growth to the right mesocolon, no unresectable areas were identified by abdominal exploration. A total gastrectomy with regional lymph node dissection and Roux-en-Y reconstruction was performed. The resected specimen showed marked infiltration to the surrounding peritoneal tissues, forming a scirrhous configuration. Because the patient had fasted for almost 1 month preoperatively, enteral feeding with sufficient glutamine was started through the jejunostomy tube on POD 4.

On POD5, he developed septic phlebitis associated with the jugular venous catheter that was promptly treated by removal of the catheter. From POD 10, massive watery diarrhea had been observed. On POD 12, his abdomen suddenly showed marked distension with severe cramping, followed by both explosive vomiting of blood-tinged contents and diarrhea. Blood investigations revealed leukocytosis $16.5 \times 10^{9} / \mathrm{l}$, C-reactive protein $100.1 \mathrm{mg} / \mathrm{l}$, urea $11.7 \mathrm{mmol} / \mathrm{l}$, creatinine $81.3 \mu \mathrm{mol} / \mathrm{l}$ and a base excess of $-4.0 \mathrm{mEq} / \mathrm{l}$. CT revealed marked dilation of the small intestine, which was filled with fluid, and HPVG occupying the left lobe of the liver (fig. 2a, b). Nonocclusive mesenteric ischemia induced by severe enteritis was diagnosed. Fluid resuscitation and continuous suction of intestinal juice through the jejunostomy tube resulted in prompt recovery. Disappearance of the HPVG was confirmed on POD 15 (fig. 2c). He was discharged in good condition on POD 43.

\section{Case 4}

A 70-year-old man underwent abdominoperineal resection for locally advanced rectal carcinoma. The primary lesion showed serosal layer invasion with infiltration to the sacrum, and the blood loss during surgery was more than 3,000 ml. On POD 2, localized necrosis seemingly due to impaired vascular perfusion of the colostomy was observed that was treated by debridement.

On POD 14, sudden steatorrhea and melena appeared. He was conscious but cyanotic and sweating profusely over his entire body. A complete blood count revealed marked normochromic anemia with a hemoglobin of $7.1 \mathrm{~g} / \mathrm{dl}$. CT showed dilation of the gastric wall with fluid collection. In addition, HPVG was recognized from the biliary tree in the left lobe of the liver to the cephalad half of the superior mesenteric vein (fig. $2 \mathrm{~d}$ ). After fluid resuscitation and sufficient volume of blood transfusion, he underwent endoscopic hemostasis by hemoclip for a hemorrhagic gastric ulcer. His general condition promptly improved. We confirmed the disappearance of HPVG by CT on POD 24 (fig. 2e). He was discharged in good condition on POD 84. 


\section{Discussion}

A prominent feature of this case series is that HPVG was detected postoperatively during the management of abdominal complications (table 1 ). In cases 1 and 2, the patients experienced abrupt onset and severe sepsis when HPVG was recognized. Neither fluid resuscitation nor surgical management improved their life-threatening status. Although we cannot sufficiently explain the pathophysiology behind these two fatal cases, we infer that HPVG was induced by hypovolemia and infection after surgery. Especially in case 2, severe sepsis with HPVG followed the onset of aspiration pneumonia and enteritis. When the postoperative infection was recognized, we should have considered treatment with sufficient fluids to avoid severe hypovolemia. In case 2, there was no sentinel sign before the onset of HPVG. Given that one important pathogenesis of HPVG is increased intestinal pressure, we retrospectively presume that early initiation of enteral feeding was associated with the appearance of HPVG in these two cases. Although the ERAS (enhanced recovery after surgery) protocol widely prevails in the management of gastrointestinal surgery, and this protocol is generally considered to play an important role in early patient recovery postoperatively, a gradual increase in enteral feeding with sufficient parenteral fluid administration is needed for critically ill patients after surgery.

In cases 3 and 4, conservative therapy resulted in favorable postoperative courses. In case 4, postoperative hypovolemia was induced by bleeding from a gastric ulcer, and no infection was observed. We believe that in case 4, neither failure of the intestinal barrier nor increased intestinal pressure was associated with the appearance of HPVG, thus leading to the early improvement in this patient.

In case 3, HPVG appeared after severe enteritis, suggesting intestinal failure. We performed fluid resuscitation with continuous drainage of the intestine through the intraoperatively placed jejunostomy tube, which yielded abundant intestinal fluids with malodorous gas. We suggest the possibility that intestinal decompression is an effective therapeutic option for severe complications accompanied by HPVG.

Although the presence of gas in the portal venous system was generally considered to be a serious intra-abdominal event, many benign cases have been put forward with the development of imaging modalities. Our search for reported cases of HPVG during the most recent 5 years (table 2) [3-32] revealed that 20 of the 31 patients were treated by a nonsurgical approach, and $22(71 \%)$ of the 31 patients recovered, suggesting that HPVG is not always a fatal sign in those patients. In addition, invasive therapy, including chemotherapy, endoscopic retrograde cholangiopancreatography, and CT-guided aspiration biopsy, was performed in $14(45.2 \%)$ of the 31 patients before onset of HPVG. Abdominal surgery is also an invasive treatment, especially in elderly patients. Care should be taken to recognize postoperative HPVG on CT imaging. Early detection and initiation of conservative therapy including fluid resuscitation and intestinal decompression are needed to obtain a favorable patient outcome.

\section{Statement of Ethics}

Written informed consent was obtained from the patients for publication of this case report and any accompanying images. The authors have no ethical conflicts to disclose. 


\section{Disclosure Statement}

All authors report no conflicts of interest related to this paper.

\section{References}

1 Wolfe JN, Evans WA: Gas in the portal veins of the liver in infants; a roentgenographic demonstration with postmortem anatomical correlation. Am J Roentgenol Radium Ther Nucl Med 1955;74:486-488.

2 Liebman PR, Patten MT, Manny J, Benfield JR, Hechtman HB: Hepatic-portal venous gas in adults: etiology, pathophysiology and clinical significance. Ann Surg 1978;187:281-287.

3 Lim JW, Kim KJ, Ye BD, Byeon JS, Myung SJ, Yang SK, Kim JH: Enterovenous fistulization: a rare complication of Crohn's disease. World J Gastroenterol 2011;17:5227-5230.

4 Lee CG, Kang HW, Song MK, Kim JH, Lee JK, Lim YJ, Koh MS, Lee JH: A case of hepatic portal venous gas as a complication of endoscopic balloon dilatation. J Korean Med Sci 2011;26:1108-1110.

5 Siciliani L, Riccardi L, Favuzzi A, Pompili M, Rapaccini G: A case of non-occlusive mesenteric ischemia and hepatic portal venous gas: not everyone knows that.... Intern Emerg Med 2011;6:563-565.

6 Chia EMY, Teo LLS, Venkatesh SK: Clinics in diagnostic imaging. Singapore Med J 2009;50:1023-1029.

7 Sawada T, Adachi Y, Noda M, Akino K, Kikuchi T, Mita H, Ishii Y, Endo T: Hepatic portal venous gas in pancreatic solitary metastasis from an esophageal squamous cell carcinoma. Hepatobiliary Pancreat Dis Int 2013;12:103-105.

8 Kadomatsu Y, Kojima T, Kohara M, Inamori M: Hepatic portal venous gas development following percutaneous endoscopic gastrostomy. Intern Med 2013;52:153.

9 Bruggen FH, Berg M, Kleij FG: A woman with an abdomen filled with gas. Ned Tijdschr Geneeskd 2012;156:A4378.

10 Ito Y, Komatsu Y: Hepatic portal venous gas. Intern Med 2012;51:2665.

11 Yuda J, Honma R, Tamura G, Omoto E: Hepatic portal venous gas associated with severe graft-versushost disease of the gastrointestinal tract. Intern Med 2012;51:2417-2421.

12 Rossi UG, Petrocelli F, Seitun S, Ferro C: Nonocclusive mesenteric ischemia in a dialysis patient with extensive vascular calcification. Am J Kidney Dis 2012;60:843-846.

13 Kashima T, Ohno Y, Tachibana M: Pneumatosis intestinalis and hepatic portal venous gas in a patient receiving sorafenib. Int J Urol 2012;19:1041-1042.

14 Ng A, Spanger M, Lubel JS: Hepatobiliary and pancreatic: emphysematous gastritis with hepatic portal venous gas. J Gastroenterol Hepatol 2012;27:1130.

15 Lee JY, Han HS, Lim SN, Shim YK, Choi YH, Lee OJ, Lee KH, Kim ST: Pneumatosis intestinalis and portal venous gas secondary to Gefitinib therapy for lung adenocarcinoma. BMC Cancer 2012;12:87.

16 Franken JM, Veen EJ: Hepatic portal venous gas. J Gastrointestin Liver Dis 2010;19:360.

17 Pua U: Percutaneous liver biopsy: a cause of hepatic portal venous gas. CMAJ 2010;182:E861.

18 Hashimoto A, Oda Y, Inagaki Y, Iguchi M, Wakita Y, Shimizu A, Murata Y, Tanaka J, Naganuma T, Nakano $\mathrm{H}$ : A case of primary leiomyosarcoma of the small bowel with hepatic portal venous gas. Nihon Shokakibyo Gakkai Zasshi 2010;107:1159-1166.

19 Artunc F, Heller S, Heuschmid M, Riessen R, Haap M: Education and imaging. Gastrointestinal: hepatic portal venous gas after cardiogenic shock and intraaortic ballon pulsation therapy. J Gastroenterol Hepatol 2010;25:644.

20 Morisaki T, Ohba K, Yoshida A, Mizuta Y, Nakao K: A case of hepatic portal venous gas caused by transient type ischemic enteritis. Nihon Shokakibyo Gakkai Zasshi 2010;107:407-415.

21 Chang CJ, Shun HC, Chuang CC: Hepatic portal venous gas induced by emphysematous pyelonephritis: a rare case in hemodialytic women. Am J Emerg Med 2009;27:1171.

22 Ortega J, Hayes JM, Antonia S: Hepatic portal venous gas in a patient with metastatic non-small cell lung cancer on bevacizumab therapy: a case report and review of the literature. Cancer Chemother Pharmacol 2009;65:187-190.

23 Mao YC, Wang JD, Wang LM: Hepatic portal venous gas caused by emphysematous pyelonephritis. Clin Gastroenterol Hepatols 2009;7:A25.

24 Bisceglia M, Simeone A, Forlano R, Andriulli A, Pilotto A: Fatal systemic venous air embolism during endoscopic retrograde cholangiopancreatography. Adv Anat Pathol 2009;16:255-262.

25 Kuo SM, Chang WK, Yu CY, Hsieh CB: Silent hepatic portal venous gas following upper gastrointestinal endoscopy. Endoscopy 2009;41:121-122.

26 Hussain A, Mahmood H, Ansari T, El-Hasani S: Pneumomediastinum, stomach wall and hepatic portal vein gas secondary to partial necrosis of the stomach wall. Singapore Med J 2009;50:166-169. Wu JM, Wang MY: Hepatic portal venous gas in necrotizing pancreatitis. Dig Surg 2009;26:119-120. 


\section{Case Reports in Gastroenterology}

\begin{tabular}{l|l}
\hline Case Rep Gastroenterol \\
\hline DOI: 10.1159/000444444 & $\begin{array}{l}\text { (c) 2016 The Author(s). Published by S. Karger AG, Basel } \\
\text { www.karger.com/crg }\end{array}$ \\
\hline
\end{tabular}

Okada et al.: Clinical Evaluation of Hepatic Portal Venous Gas after Abdominal Surgery

28

29

30

31

32

Sen M, Akpinar A, Inan A, Sişman M, Dener C, Akin K: Extensive hepatic-portal and mesenteric venous gas due to sigmoid diverticulitis. World J Gastroenterol 2009;15:879-881.

Rankin I, Sheth H: Hepatic portal venous gas: comparison of two cases. Case Rep Surg 2013;637951.

Allaparthi SB, Anand CP: Acute gastric dilatation: a transient cause of hepatic portal venous gas-case report and review of the literature. Case Rep Gastrointest Med 2013;723160.

Diana M, Paroz A, Demartines N, Schäfer M: Retroperitoneal abscess with concomitant hepatic portal venous gas and rectal perforation: a rare triad of complications of acute appendicitis. A case report. World J Emerg Surg 2010;5:3.

Kesarwani V, Ghelani DR, Reece G: Hepatic portal venous gas: a case report and review of literature. Indian J Crit Care Med 2009;13:99-102.
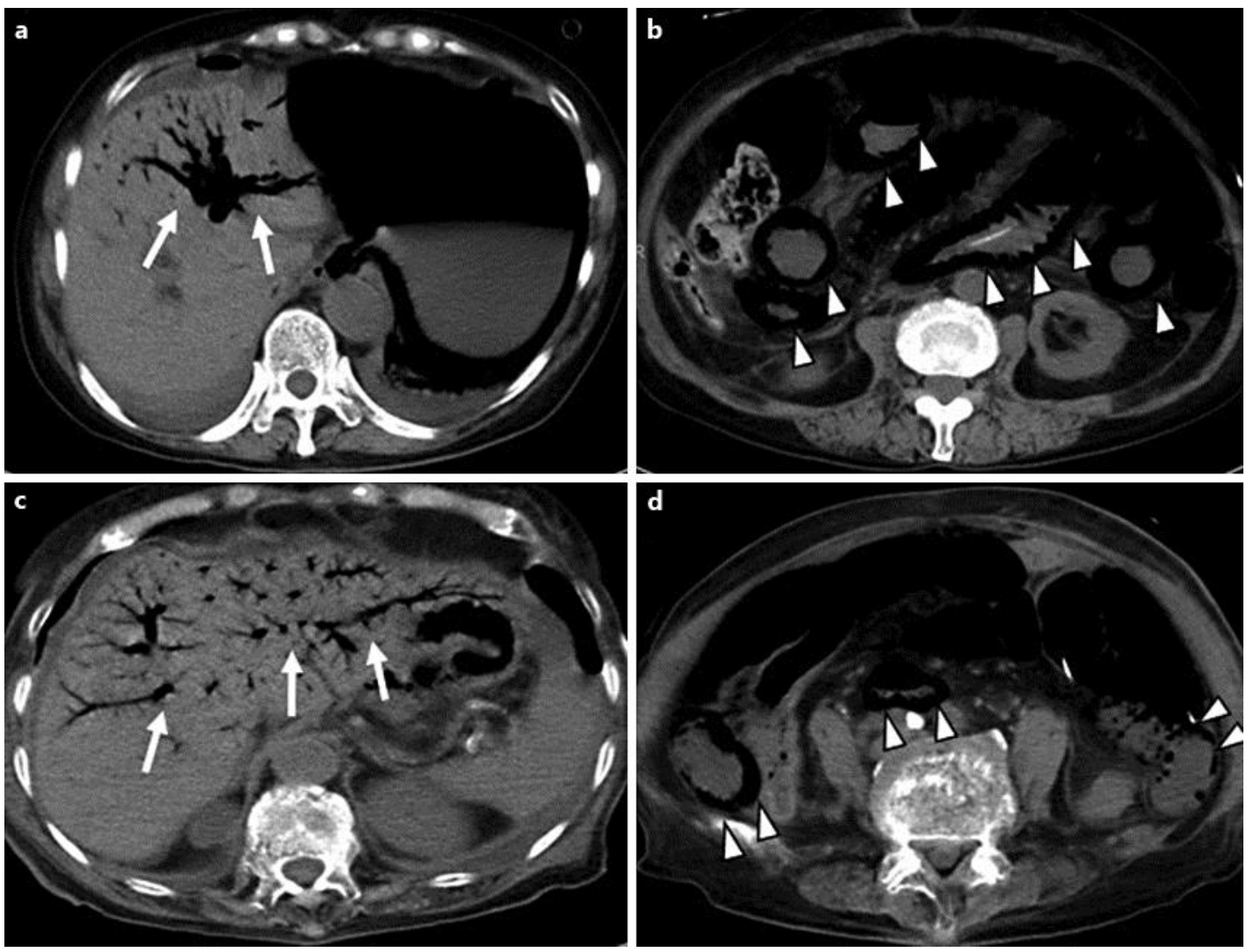

Fig. 1. Abdominal CT findings of cases 1 and 2. HPVG infiltrates throughout the intrahepatic portal branches (arrows) [case 1 (a); case 2 (c)] accompanied by diffuse intraluminal gas along the small intestinal wall (arrowheads) [case 1 (b); case $2(\mathbf{d})]$. 


\section{Case Reports in Gastroenterology

\begin{tabular}{l|l}
\hline Case Rep Gastroenterol \\
\hline DOI: 10.1159/000444444 & $\begin{array}{l}\text { ○ } 2016 \text { The Author(s). Published by S. Karger AG, Basel } \\
\text { www.karger.com/crg }\end{array}$ \\
\hline
\end{tabular}
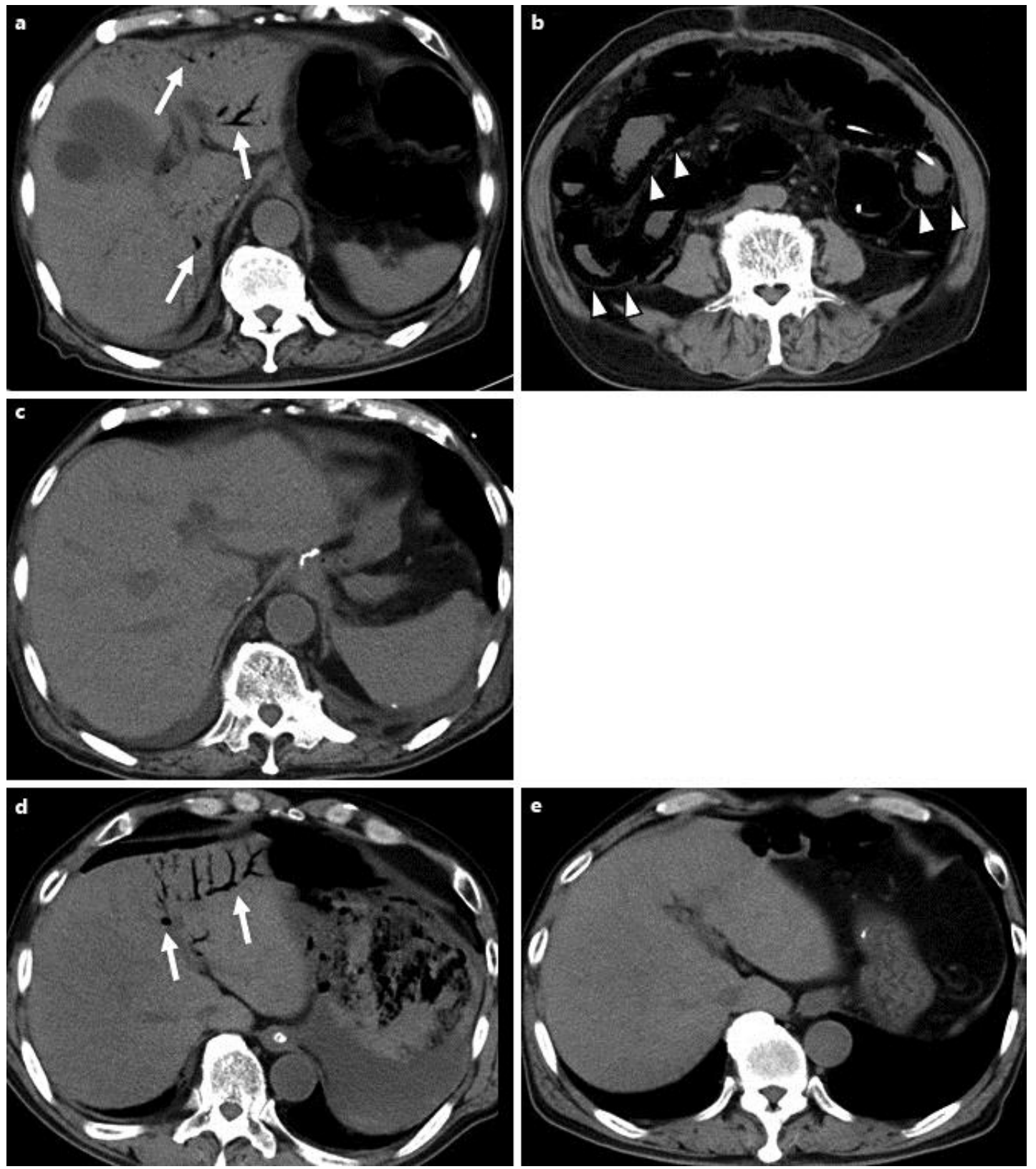

Fig. 2. Abdominal CT findings of cases 3 and 4 HPVG (arrows) [case 3 (a); case 4 (d)] with intraluminal gas of the small intestine (arrowheads) [case 3 (b)] are observed. Disappearance of HPVG is confirmed by CT after conservative treatment [case $3(\mathbf{c})$; case $4(\mathbf{e})]$. 


\begin{tabular}{ll|l} 
Case Reports in & \begin{tabular}{l} 
Case Rep Gastroenterol \\
\cline { 2 - 3 } Gastroenterology $10.1159 / 000444444$
\end{tabular} & $\begin{array}{l}\text { ○ 2016 The Author(s). Published by S. Karger AG, Basel } \\
\text { www.karger.com/crg }\end{array}$ \\
\cline { 2 - 3 } & Okada et al.: Clinical Evaluation of Hepatic Portal Venous Gas after Abdominal Surgery
\end{tabular}

Table 1. Summary of the clinical features of our four cases

\begin{tabular}{|c|c|c|c|c|c|c|c|}
\hline $\begin{array}{l}\text { Case } \\
\text { No. }\end{array}$ & $\begin{array}{l}\text { Age/ } \\
\text { sex }\end{array}$ & Disease & Operation & $\begin{array}{l}\text { Onset } \\
\text { time of } \\
\text { HPVG }\end{array}$ & Symptom & Treatment & $\begin{array}{l}\text { Out- } \\
\text { come }\end{array}$ \\
\hline 1 & $70 / \mathrm{F}$ & bile duct carcinoma & $\begin{array}{l}\text { pylorus-preserving pancreatoduo- } \\
\text { denectomy }\end{array}$ & POD 5 & loss of consciousness & operation & death \\
\hline 2 & $82 / \mathrm{F}$ & gastric carcinoma & total gastrectomy & POD 15 & diarrhea & conservative & death \\
\hline 3 & $81 / \mathrm{M}$ & gastric carcinoma & total gastrectomy & POD 12 & diarrhea hematemesis & conservative & alive \\
\hline 4 & $70 / \mathrm{M}$ & rectal carcinoma & abdominoperineal resection & POD 14 & melena & conservative & alive \\
\hline
\end{tabular}


Table 2. Summary of the clinical features of reported cases of HPVG during the most recent 5 years [3-32]

\begin{tabular}{|c|c|c|c|}
\hline All cases & 31 & Presence of sepsis & 5 \\
\hline Sex & & Presence of shock & 6 \\
\hline Male & 15 & Treatment & \\
\hline Female & 14 & Conservative & 17 \\
\hline Not mentioned & 2 & Operation & 10 \\
\hline Age & & Appendectomy and Hartmann & 1 \\
\hline$<65$ & 16 & Gastrojejunostomy & 1 \\
\hline$\geq 65$ & 15 & Hartmann & 1 \\
\hline Past history & & Ileocecal resection & 2 \\
\hline Diabetes mellitus & 9 & Jejunum resection & 2 \\
\hline Renal disease & 5 & Fibrotic adhesion resection & 1 \\
\hline Hemodialysis & 3 & Right hemicolectomy & 2 \\
\hline Symptom & & Percutaneous drainage & 3 \\
\hline Abdominal pain & 19 & Not mentioned & 1 \\
\hline Abdominal discomfort & 1 & Outcome & \\
\hline Abdominal distension & 5 & Alive & 22 \\
\hline Vomiting & 8 & Death & 7 \\
\hline Nausea & 2 & Not mentioned & 2 \\
\hline Diarrhea & 2 & Survival time in fetal cases $(n=7)$ & \\
\hline Fever & 5 & $\leq 1$ day & 2 \\
\hline Asymptomatic & 3 & 1 day $<, \leq 3$ days & 3 \\
\hline Diagnosis (investigation) & & 3 days $<, \leq 7$ days & 1 \\
\hline CT & 29 & $\leq 7$ days & 1 \\
\hline Abdominal radiography & 2 & & \\
\hline Ultrasonography & 3 & & \\
\hline Autopsy & 1 & & \\
\hline \multicolumn{4}{|l|}{ Cases undergone some interventions } \\
\hline before development of HPVG & 14 & & \\
\hline Right hemicolectom & 1 & & \\
\hline PEG & 1 & & \\
\hline CT-guided liver biopsy & 1 & & \\
\hline Gastrointestinal endoscopy & 1 & & \\
\hline Endoscopic balloon dilatation & 1 & & \\
\hline ERCP for bile duct stones & 1 & & \\
\hline Angiogram for AMI & 1 & & \\
\hline IABP & 1 & & \\
\hline Dialysis & 1 & & \\
\hline Allo-PBSCT & 1 & & \\
\hline Gefitinib, sorafenib, bevacizumab & 3 & & \\
\hline Budesonide for Crohn's disease & 1 & & \\
\hline
\end{tabular}

